\title{
O SERTÃO E O SERTANEJO: um Brasil de vários sertões
}

\author{
Paula Regina Pereira dos Santos Marques Dias ${ }^{1}$ \\ ${ }^{1}$ Universidade do Vale do Rio dos Sinos (UNISINOS-RS), São Leopoldo, RS, Brasil.
}

Resumo: Este artigo tem Como objetivo apresentar o sertão e o sertanejo com diferentes significados e olhares. O Brasil é um país de vários sertões, em que o espaço analisado faz fronteira com um litoral que recebeu outra construção social, cultural e geográfica. O litoral muitas vezes é visto como o belo, o Jardim do Éden, a exuberância da natureza, enquanto o sertão é visto pelos aspectos geográficos deteriorados, seco, com natureza prejudicada pela "divindade"'. Deste modo, por meio de pesquisa bibliográfica, com análise de textos e de conteúdo, buscou-se entender a variedade de sertões que o Brasil possui, bem como observar o homem sertanejo que ali vive, visto como o valente, mas também aquele que ensina o método do "jeitinho" brasileiro. Compreende-se que dentro do pensamento social brasileiro as figuras do sertão e do sertanejo são apresentadas com o aspecto do regionalismo, observado não somente em razão do lugar geográfico que assume, mas também da sua posição social e cultural.

Palavras-chave: Sertão. Sertanejo. Olhares. Brasil.

Abstract: This article aims to present the sertão and sertanejo with different meanings and perceptions. Brazil is a country of several sertões (up-country regions far inside the country), in which the analyzed space borders on a coast area that received another social, cultural and geographical construction. The coastline is often seen as the beautiful, the Garden of Eden, the exuberance of nature, while the hinterland is seen by geographically deteriorated, dry, with nature prejudiced by "a deity." In this way, through a bibliographical research, with analysis of texts and content, it was sought to understand the variety of sertões that Brazil possesses, as well as to observe the sertanejo man who lives there, seen as the brave, but also that which teaches the "Jeitinho Brasileiro", which consists in a group of ethically unorthodox behaviors, usually related to bribery and leverage, very common amongst Brazilian people. It is understood that within the Brazilian social thought the figures of the sertão and the sertanejo are presented with the aspect of regionalism, observed not only because of the geographic place that it assumes, but also of its social and cultural position.

Keywords: Sertão. Sertanejo. Perceptions. Brazil.

Como citar: DIAS, P. R. P. S. M. O sertão e o sertanejo: um Brasil de vários sertões. Revista Científica Novas Configurações Diálogos Plurais, Luziânia, v. 1, n.1, p. 4-11, 2020. https://doi.org/.10.4322/2675-4177.2020.002

\section{INTRODUÇÃO}

O sertão e o sertanejo possuem uma construção conceitual não muito homogênea. Este fato devese ao motivo de que existem diferentes significados e significações aos quais lhes são dados durante o passar do tempo e a depender dos aspectos que são analisados.

O sertão na visão do século XVI era aquele que se contrapunha ao litoral, zona terrestre conquistada ou descoberta. No entanto, o sertanejo era alguém desconhecido, provavelmente composto de povos indígenas. Deste modo, Oliveira (1998, p. 197) aponta que este lugar visto pelo homem da cidade era um "espaço desconhecido, habitado por índios, feras e seres indomáveis".

Oliveira (1998, p.196) informa ainda que:

\section{Apoio financeiro: Nenhum.}

Conflitos de interesses: Os autores declaram não haver nenhum conflito de interesse.

Correspondência: paulaitz@hotmail.com

Recebido: 03 Abr 2020.

Aprovado: 20 Mai 2020

Editor: Marcelo Máximo Purificação.

Este é um artigo publicado em acesso aberto (Open Access) sob a licença Creative Commons Attribution, que permite uso, distribuição e reprodução em qualquer meio, sem restrições desde que o trabalho original seja corretamente citado. 
O lugar geográfico ou social identificado como sertão acompanha este caminho que recebe ora uma avaliação positiva, ora negativa. As definições de sertão fazem referência a traços geográficos, demográficos e culturais: região agreste, semi-árida, longe do litoral, distante de povoações ou de terras cultivadas, pouco povoada e onde predominam tradições e costumes antigos. [...] A força de seu habitante aparece relacionada à capacidade de interagir com a natureza múltipla. O cabra - o cangaceiro - aparece como a encarnação do herói sertanejo. Para além destes atributos, aparece no imaginário social a ideia de que não há um sertão mas muitos sertões e que o sertão pode e deve ser tomado como metáfora do Brasil. (grifou-se).

Com o passar dos séculos e com o desbravamento pelos bandeirantes é que se conheceu a força do sertanejo, sendo que hoje é bem característica a sua miscigenação. Porém, a construção do sertão e do sertanejo é apresentado dentro da categoria de regionalismo.

Vários autores na literatura brasileira trazem diversas formas de olhar o sertão e o sertanejo: Euclides da Cunha, tendo o sertão como inferno, Guimarães Rosa, do sertão purgatório, lugar de penitência e reflexão, Catulo da Paixão Cearense e Afonso Arinos, vislumbrando o sertão com a linha romântica de paraíso e, ainda, José de Alencar, Bernardo Guimarães, Franklin Távora e Alfredo Descragnolle Taunay, todos observados nos textos de Lúcia Lippi Oliveira, Nísia Trindade Lima, Marilena Chauí, Luiz Carlos Lima, entre outros.

Com a metodologia erigida na pesquisa bibliográfica e análise de textos e de conteúdo, o objetivo central é o de entender a variedade de sertões que o Brasil possui, bem como observar o homem sertanejo que ali vive. Como os vários autores enxergaram no decorrer do tempo as figuras do sertão e do sertanejo no Brasil? Como eles percebem a construção histórica desse espaço e desse povo?

Logo, esse artigo aborda primeiramente as visões que são tidas do sertão e do sertanejo na literatura brasileira, a visão paradisíaca, de purgatório e de inferno, relatando situações na história brasileira que referenda tais situações.

Posteriormente, vê-se a realidade atual de vários sertões brasileiros que são apresentadas de acordo com o regionalismo, sua forma geográfica, cultural e de miscigenação. Por fim, entende-se que a história do sertão e do sertanejo ainda está em conclusão, não é totalmente acabada.

\title{
2 MEU SERTÃO, MEU SERTANEJO ....
}

No Brasil, a palavra sertão recebeu diversos significados. O primeiro se deu com a chegada dos portugueses, quando abarcaram no território brasileiro e fizeram a diferenciação a partir do seu olhar do litoral (IBGE, 2009). Pode-se constatar através do texto de Pero Vaz de Caminha:

Esta terra, Senhor, parece-me que, da ponta que mais contra o sul vimos, até à outra ponta que contra o norte vem, de que nós deste porto houvemos vista, será tamanha que haverá nela bem vinte ou vinte e cinco léguas de costa. [...] De ponta a ponta é toda praia... muito chã e muito formosa. Pelo sertão nos pareceu, vista do mar, muito grande; porque a estender olhos, não podíamos ver senão terra e arvoredos -- terra que nos parecia muito extensa (CAMINHA, online, grifo nosso).

Etimologicamente, a palavra sertão tem duas origens, sendo uma africana e a outra referente à vegetação, conforme explicitado no Atlas do IBGE:

\begin{abstract}
Há, basicamente, duas vertentes interpretativas das origens etimológicas de sertão. Uma atribui a origem do termo à palavra africana mulcetão, que designava terras distantes da costa, mediterrâneas, e ao ser incorporada à língua portuguesa assumiu a forma certão, mais tarde sertão (BARROSO apud GALVÃO, 2001, p. 16; NEVES; MIGUEL, 2007, p. 9). A outra vertente duvida da evolução do termo mulcetão para sertão e considera mais provável que a palavra tenha origem em "sertanus, advinda de sertum, particípio passado de sero, serui, sere", que se traduziria por "entrelaçar", "entrançar", com o sentido de "o que está entrelaçado", numa alusão à "vegetação contínua" (MEYER-LÜBKE apud NEVES; MIGUEL, 2007, p. 10). De qualquer forma, como se viu anteriormente, o primeiro documento em língua portuguesa que descreve o território brasileiro - a carta de Pero Vaz de Caminha - utiliza o termo sertão para referir-se a terras distantes do litoral. Neves e Miguel (2007, p. 10) reforçam esse argumento citando ainda as cartas de doação das capitanias hereditárias, onde o termo aparece com o mesmo sentido. (IBGE, 2009, p. 11)
\end{abstract}

Percebe-se que nos primórdios da nossa história, a palavra sertão era vinculada ao interior, ao oposto de litoral, às terras distantes da costa, denotando-se a percepção de fronteira, com a criação do antagonismo entre o litoral e o sertão.

Posteriormente, a identidade nacional foi construída após a chamada "ocupação do vazio", ou seja, o avanço do movimento das bandeiras responsável pelo aumento do espaço territorial da colônia portuguesa nos séculos XVII e XVIII:

Confirmando a importância do espaço na construção da identidade nacional, encontra-se a questão do ponto zero da história do país, do evento histórico original que fez nascer a nação: as bandeiras. Movimento de 
expansão territorial, de ocupação do "vazio" que teve lugar no período colonial, bandeira e bandeirante, assim como sertão e sertanejo, volta e meia retornam à ordem do dia como componentes do imaginário nacional. (OLIVEIRA, 1998, p. 203).

O Atlas das Representações Literárias de Regiões Brasileiras, Sertões Brasileiros I, volume 2 (2009) informa que ao longo do processo de ocupação ocorreu uma evolução para outros significados:

\begin{abstract}
Ao longo do processo de ocupação acontece a evolução para outros significados. O que, inicialmente, designava terras distantes do litoral assumiu novos conteúdos à medida que as estruturas do poder metropolitano se estabeleciam no território, criando a diferenciação de áreas. Como a ocupação se firmava no litoral e a interiorização implicava a penetração em terras densamente florestadas, acidentadas e povoadas por índios (quase sempre tidos como bárbaros pelos europeus), ao sentido primeiro foi adicionado o de terra ignota, desconhecida, perigosa. (IBGE, 2009, p. 11)
\end{abstract}

Os bandeirantes avançaram nos sertões conquistando e dizimando povos sertanejos (em um certo momento, índios). Oliveira (2000, p. 82) descreve que:

O primeiro momento das bandeiras, caracterizado pelo domínio, destruição e aprisionamento dos índios, apresenta problemas para a história do Brasil no século XIX, já que os índios passam a ser identificados com a liberdade e com a natureza. Por outro lado, a história do país se volta para outros temas ligados à formação da nação. No Instituto Histórico e Geográfico Brasileiro os temas considerados relevantes estão vinculados à administração colonial e aos grandes feitos dos governantes.

Nos sertões maranhenses não foi diferente. Carlota Carvalho (2011) aponta que comandados por Manoel Assumpção e seus auxiliares, Elias de Barros e outros, houve a exterminação de todas as nações que "negavam a identidade humana" por não aceitar o batismo, entre elas estavam os macamecrans, poremecrans, xavantes e caracatigês.

No entanto, as bandeiras e os bandeirantes foram centro de polêmica de imagens conflitantes na construção da memória histórica do país, ora sendo acusados de assassinos cruéis, ora sendo enaltecidos como verdadeiros construtores da nacionalidade pela bravura e integridade de sua conduta. (OLIVEIRA, 2000, p. 80)

Após esse movimento a análise sobre o sertão e o sertanejo foi sendo alterada com o passar dos séculos. O olhar sobre o sertão e o sertanejo destoa a depender de quem e como se observa. Como Cardoso (1988, p. 348) explica:

[...] O olhar não descansa sobre a paisagem contínua de um espaço inteiramente articulado, mas se enreda nos interstícios de extensões descontínuas, desconcertadas pelo estranhamento. Aqui o olho defronta constantemente limites, lacunas, divisões e alteridade, conforma-se a um espaço aberto, fragmentado e lacerado. Assim, trinca e se rompe a superfície lisa e luminosa antes oferecida à visão, dando lugar a um lusco-fusco de zonas claras e escuras, que se apresentam e se esquivam à totalização. (grifou-se)

O sertão aparece num contexto histórico com diversos olhares e perspectivas dentro da literatura brasileira. Oliveira orienta que o sertão aparece pelo menos sob três perspectivas:

\begin{abstract}
A primeira é o "sertão como paraíso", que se expressa basicamente no romantismo. Evoca-se um paraíso perdido em que tudo era perfeito, belo e justo e cuja linguagem retrataria uma pureza original a ser apreciada e preservada. Esta linha romântica se mantém no século XX por figuras como as de Catulo da Paixão Cearense, no âmbito da cultura popular, e Afonso Arinos, na veia erudita e de elite.

A segunda forma de lidar com o sertão o associa ao inferno. O destempero da natureza, o desespero dos que por ele perambulam (retirantes, cangaceiros, volantes, beatos), a violência como código de conduta, o fatalismo, são os principais traços apontados. Euclides da Cunha é certamente um dos representantes desta leitura do espaço do sertão como inferno ainda que sua explicação seja de ordem político-cultural.

Por fim, o sertão é o purgatório. Lugar de passagem, de travessia, definido pelo exercício da liberdade e pela dramaticidade da escolha de cada um. Identificado como lugar de penitência e de reflexão, o sertão aparece como reino a ser desencantado e decifrado. Aqui estamos no mundo de Guimarães Rosa (OLIVEIRA, 1998, p. 199)
\end{abstract}

Oliveira (1998) aponta que Euclides da Cunha consegue inverter a compreensão de sertão de seu tempo. Em sua obra, o sertanejo é visto como retrógrado e não degenerado. $\mathrm{O}$ atraso analisado desse povo decorre ao abandono que foi relegado diferenciando os tempos sociais do litoral e do sertão e não pelos condicionamentos e determinações de ordem genética.

Euclides da Cunha (1995) ainda verifica que essa diferença entre os tempos sociais poderia ser diminuída por ações governamentais. No entanto, como Oliveira (1998) se posiciona salientando de que isso não passou de um sonho romântico de juntar tempos históricos e sociais distintos e que foi abandonado por Euclides da Cunha ao desacreditar na República como um regime capaz de construir a nação. 
No início do século XX a análise do lugar do sertão, seja em sua compleição geográfica, seja em seu espaço social que ocupava na nação, recebia definições positivas e negativas, ficando certo que o sertanejo era um herói por ali conseguir "sobreviver".

[...] Não nos enganemos, escreve Euclides, com a aparência raquítica, o andar e a fala preguiçosos, pois sob essa aparência esconde-se aquele que luta contra a fúria dos elementos. Aos "mestiços neurastêmicos do litoral" é preciso contrapor o sertanejo, aquele que “é, antes de tudo, um forte". (CHAUI, 2004, p.67)

O sertão é observado, concebido, analisado de formas diferentes a depender de quem o enxerga. Oliveira aponta que:

O sertão para o habitante da cidade, aparece como espaço desconhecido, habitado por índios, feras e seres indomáveis. Para o bandeirante, era o interior perigoso, mas fonte de riquezas. Para os governantes lusos das capitanias, era exílio temporário. Para os expulsos da sociedade colonial significava liberdade e esperança de uma vida melhor. (OLIVEIRA, 2000, p. 71).

Em qualquer conceituação pode-se analisar que o referencial não está intrinsicamente relacionado às condições geográficas, mas parte do olhar de quem se depara com aquele espaço diferenciado. Euclides da Cunha ao partir para a Guerra de Canudos estava com uma percepção já preconcebida do que era o sertão, com seus "preconceitos" formulados. No entanto, ao se deparar com a realidade, procura se desprender das fórmulas prontas e passa a analisar cada detalhe, da localidade e do povo que ali vivia. Para Euclides da Cunha (apud CHAUI, 2004, p. 67) o sertão é:

[...] uma paragem impressionante.

As condições estruturais da terra lá se vincularam à violência máxima dos agentes exteriores para o desenho de relevos estupendos. O regime torrencial dos climas excessivos, sobrevindo de súbito, depois das insolações demoradas, e embatendo naqueles pendores, expôs há muito, arrebatando-lhes para longe todos os elementos degradados [...] dispondo-se em cenários em que se ressalta, predominantemente, o aspecto atormentado das paisagens [...] no contorcido dos leitos secos dos ribeirões efêmeros, no constrito das gargantas e no quase convulsivo de uma flora decídua embaralhada em esgalhos - é de algum modo o martírio da terra, brutalmente golpeada pelos elementos [...].

As forças que trabalham a terra atacam-na na contextura íntima e na superfície, sem intervalos na ação demolidora, substituindo-se, com intercadência invariável, as duas estações únicas da região.

Dissociam-se nos verões queimosos; degradam-na nos invernos torrenciais".

A visão do sertão é tida como essa mistura de relevo exuberante e aridez, paisagem atormentada. E o sertanejo? Escórcio (2016, p. 35) menciona que:

[...] no romance "Usina" de José Lins do Rego estão presentes os dissabores da vida do sertanejo, a imagem dessas pessoas como "verdadeiros cacos humanos", "flagelados pela seca", associando esse contexto às questões climáticas. Segundo Buriti \& Aguiar (2012, p. 12): "Mesmo nessa literatura sobre o litoral, a seca é situada como a causa de todos os "pavores" na vida dos sertanejos, confirmando toda aquela conotação fatalista (...) no que se refere às representações do Sertão nos períodos de seca".

O sertanejo é olhado também como aquele que sempre tenta conseguir uma forma para sobreviver, mesmo em meio a tantas dificuldades. É instigado e estimulado pela sua cultura, musicalidade diferenciada, e, principalmente, o sertanejo é tido como aquele ser apegado a religiosidade. Sua forma de (sobre)viver também o faz ser reconhecido pela prática e pelo ensino do "jeitinho" brasileiro de ser.

$\mathrm{Na}$ literatura regional, pode-se perceber na obra de Ariano Suassuna, o Auto da Compadecida, em que se demonstra geográfica, social e culturalmente como é o sertão e o sertanejo. Os indivíduos que estão representados nesta história marcam bem a figura que transparece do sertanejo ora trabalhador, ora preguiçoso, ora visto como aquele que sempre tem um jeitinho para escapar das punições. Transcreve-se um trecho que se visualiza tal situação:

\section{A COMPADECIDA}

João foi um pobre como nós, meu filho. Teve de suportar as maiores dificuldades, numa terra seca e pobre como a nossa.

Não o condene, deixe João ir para o purgatório.

JOÃO GRILO

Para o purgatório? Não, não faça isso assim não. (Chamando a Compadecida à parte.) Não repare eu dizer isso mas é que o diabo é muito negociante e com esse povo a gente pede o mais para impressionar. A senhora pede o céu, porque aí o acordo fica mais fácil a respeito do purgatório. A COMPADECIDA

Isso dá certo lá no sertão, João! Aqui se passa tudo de outro jeito! Que é isso? Não confia mais na sua advogada? (grifou-se) (SUASSUNA, 1955, p. 183) 
Este trecho demonstra em primeiro lugar a visão que se tem do sertanejo. A "Compadecida" coloca a figura de João como sendo pobre, tendo que suportar dificuldades de uma terra com seca e pobre, justificando seus ardis "jeitinho" para conseguir tudo o que necessitava.

No entanto, mesmo com a defesa da "Compadecida", sendo julgado, o sertanejo Grilo procura arquitetar uma forma de conseguir o que quer, quando diz "A senhora pede o céu, porque aí o acordo fica mais fácil a respeito do purgatório". É alertado que no céu as coisas não funcionam com esse jeitinho e que isso dá certo no sertão.

No período revelado por Euclides da Cunha observa-se que as populações sertanejas eram constituídas com preponderância de "sangue tapuia". O autor aponta que:

\begin{abstract}
De sorte que, hoje, quem atravessa aqueles lugares observa uma uniformidade notável entre os que os povoam: feições e estaturas variando ligeiramente em torno de um modelo único, dando a impressão de um tipo antropológico invariável, logo ao primeiro lance de vistas distinto do mestiço proteiforme do litoral. Porque enquanto este patenteia todos os cambiantes da cor e se erige ainda indefinidos, segundo o predomínio variável dos seus agentes formadores, o homem do sertão parece feito por um molde único, revelando quase os mesmos caracteres físicos, a mesma tez, variando brevemente do mamaluco bronzeado ao cafuz trigueiro; cabelo corredio e duro ou levemente ondeado; a mesma envergadura atlética, e os mesmos caracteres morais traduzindo-se nas mesmas superstições, nos mesmos vícios, e nas mesmas virtudes. (CUNHA, 1995, p. 45).
\end{abstract}

Na década de 1920, o sertanejo ficou estigmatizado pela caricatura do Jeca Tatu, a quem designava não em ser, mas estar daquele modo em decorrência das misérias, da desnutrição e das moléstias que assolavam o interior do país. Monteiro Lobato (apud PALMA, 2006) informa que "Este funesto parasita da terra é o CABOCLO, espécie de homem baldio, semi-nômade, inadaptável à civilização[...]".

Palma (2006) salienta que Rui Barbosa cita Jeca Tatu no Teatro Lírico, descrevendo-o tal como Lobato como o "símbolo de preguiça e fatalismo, de sonolência e imprevisão, de esterilidade e tristeza, de subserviência e embotamento".

No entanto, o próprio Lobato ao conhecer a realidade sanitarista das regiões sertanejas vai desmistificando e impondo a fatalidade do caboclo ao problema de um país que não cuida do seu povo. Lobato (apu PALMA, 2006) se redime: "Eu ignorava que eras assim, meu caro Jeca, por motivo de doenças tremendas. Está provado que tens no sangue e nas tripas todo um jardim zoológico da pior espécie. É essa bicharia cruel que te faz papudo, feio, molenga, inerte."

Linhares informa que:

[...] o caipira é um zeloso observador de regras sociais, ofendendo-se facilmente com alguma desfeita; um café ou um almoço não aceitos, uma visita não realizada ou qualquer outra forma de cortesia da qual se faz pouco caso, tudo isso, pode ser entendido como desfeita; uma palavra inoportuna pode ofendê-lo profundamente em sua honra e dignidade; em tempos não muito distantes, como será visto posteriormente, uma palavra inadequada era motivo para brigas que, não muito raro, resultavam em mortes. (LINHARES, 2005, p.58/59).

Portanto, o sertanejo tem a conotação histórica que foi se modificando, mas que atualmente na mentalidade do brasileiro do "litoral" é visualizada e estigmatizada ao mesmo tempo em todas as facetas apontadas. Logo, na mentalidade do observador o sertanejo é o habitante do interior, é o guerreiro, é o herói, é o degenerado, é o Jeca Tatu, o homem rural, o caipira, o do mato, o religioso.

\title{
3 UM BRASIL DE VÁRIOS SERTÕES
}

O Brasil pode ser considerado um país de vários sertões, desde aqueles caracterizados por sua condição geográfica, como por aqueles reconhecidos assim por suas questões culturais e sociais.

A opção pelo termo sertão para designar porções do território brasileiro está associada à compreensão de que há dinâmicas diferenciadas em sua ocupação, e elas estão relacionadas tanto à configuração desse território quanto às conjunturas política e econômica do mundo europeu dos Séculos XVI, XVII e XVIII, que influenciaram profundamente os rumos de sua apropriação. (IBGE, 2009, p. 10)

Pelo Atlas das Representações Literárias de Regiões Brasileiras, Sertões Brasileiros I, volume 2 (2009), o sertão abarca regiões dos atuais Estados de Minas Gerais, São Paulo, Rio de Janeiro, Espírito Santo, Bahia, Pernambuco, Paraíba e Ceará. No entanto, observa-se que até a Amazônia já foi considerada sertão, inclusive Euclides da Cunha iniciou os escritos sobre o assunto. Desta maneira: 
Não se supõe, com isso, que apenas aquelas regiões incluídas nos dois volumes de Sertões brasileiros abarcam ou abarcaram áreas que um dia foram identificadas como sertão. Sertão é, na verdade, uma palavra de significação ampla e movediça na língua portuguesa, o que faz com que diferentes segmentos do território, em vários momentos históricos, tenham recebido a alcunha de sertão. Até mesmo parcelas da região Amazônica já foram assim identificadas. A lógica dos recortes assumidos para cada um dos volumes procura contemplar os aspectos mais marcantes no processo de ocupação. As grandes marcas da região Amazônica são, sem dúvida alguma, a bacia hidrográfica e a floresta, do mesmo modo que a ocupação da costa brasileira foi marcada pela condição de área de defesa, com o estabelecimento de fortes marcando as primeiras instalações, seguidas das atividades de extração do pau-brasil e da cultura de cana-de-açúcar. (IBGE, 2009, p. 10, grifouse)

Perceba-se que até mesmo a Amazônia já foi em algum momento identificada como sertão, assim como é apresentado no trecho acima do Atlas, e como bem a designou Euclides da Cunha nos seus escritos não concluídos "Um paraíso perdido", em que demonstrava "a natureza imprópria a ocupação humana e adversária do homem" (OLIVEIRA, 1998, p. 201).

Em relação ao sertão do nordeste, Ab'Saber alega que somente o conhecimento isolado das bases físicas e ecológicas não consegue explicar o "grande drama" vivenciado pelos agrupamentos humanos que ali vivem. E ressalta que:

[...] a análise das condicionantes do meio natural constitui uma prévia decisiva para explicar causas básicas de uma questão que se insere no cruzamento dos fatos físicos, ecológicos e sociais. Nenhuma solução ou feixe de soluções dirigidas para a resolução dos problemas do Nordeste brasileiro poderá abstrair o comportamento do seu meio ambiente, inclusive no que diz respeito à fisiologia da paisagem, aos tipos de tecidos ecológicos e à utilização adequada dos escassos recursos hídricos disponíveis. (AB’SABER, 1999).

A relação direta entre a fisiografia, a ecologia e as condições sociais, trazidas por Ab'Saber (1999), dão conta de que o sertão é tido como "região paradoxal em relação aos demais tipos de espaços geográficos do mundo subdesenvolvido". O geógrafo informa que "o grau de diferenciação de seus espaços econômicos e sociais é inegavelmente baixo". Contudo, também aponta que "é uma região sob intervenção, onde o planejamento estatal define projetos e incentivos econômicos de alcance desigual, mediante programas incompletos e desintegrados de desenvolvimento regional".

Ab'Saber continua informando que:

[... ] revelando o caráter híbrido de seu perfil sócio-econômico atual, combina arcaísmos generalizados com importantes elementos pontuais de modernização, tais como uma razoável hierarquização urbana, um bom sistema de rodovias asfaltadas que garante as ligações intra e interregionais, e uma rede de açudes, com diferentes possibilidades de fornecimento de água para áreas irrigáveis de planícies de inundação (vazantes). Destaca-se sobre tudo isso, a extraordinária área de irrigação de Petrolina (Pernambuco) e Juazeiro (Bahia), no médio vale inferior do São Francisco. (AB’SABER, 1999).

Contudo, não é somente na região nordeste do Brasil que é caracterizada como sertão. Com base nos estudos firmados pelo Atlas das Representações Literárias de Regiões Brasileiras, Sertões Brasileiros I, volume 2 (2009), o sertão compreende ainda a região sudeste com os Estados de Minas Gerais, São Paulo, Rio de Janeiro, Espírito Santo.

Identificados pelo Atlas como Sertões do Leste Regiões do vale do Paraíba, da Zona da Mata mineira e do vale do Rio Doce e os Sertões de Ouro a região mineira. O Atlas explica que:

Em História, uma região é bem mais do que o solo: é antes de tudo a história que sobre ele se desenrolou, o que requer considerar que sejam também consideradas no jogo outras variáveis: o vocabulário, o sotaque, a culinária, as festas, os santos de devoção, a música. Numa palavra, tudo o que hoje consideraríamos a herança imaterial de uma dada sociedade. (IBGE, 2009, p. 23, grifou-se).

Ferreira (2004 apud IBGE, 2009, p. 25) salienta que a "a porção territorial objeto deste estudo certamente não corresponde a uma imagem habitual de sertão, uma vez que consiste em área relativamente próxima ao litoral e originalmente recoberta pela floresta tropical latifoliada, a Mata Atlântica".

No entanto, se verifica que há um "estranhamento inicial” porque "historicamente convencionouse como conceito mais afeito ao termo sertão aquele vinculado às áreas distantes do litoral, situadas no interior dos continentes, pouco povoadas, geralmente caracterizadas por baixa pluviosidade e vegetação xerófita". (FERREIRA, 2004, apud IBGE, 2009, p. 25).

Atualmente, além das porções reconhecidamente como sertões por conta de uma herança histórica material, tem-se também a análise de estudo geográfico, fisiográfico da região. Por isso, integrando a parte do sertão brasileiro, os sertões do Leste localizado na região sudeste do país, tem as 
regiões reconhecidas do Vale do Rio Paraíba do Sul, Zona da Mata mineira e vale do Rio Doce, como anteriormente mencionado. Entende-se, ainda, que:

\begin{abstract}
Em muitos casos, todavia, há indicações de que esses sertões se espraiavam para além dessa circunscrição, avançando sobre outras áreas dos atuais Estados de São Paulo, Rio de Janeiro, Minas Gerais e Espírito Santo. Como bem indica a forma plural do topônimo "sertões", trata-se de um quadro que reúne várias áreas assim denominadas, como, por exemplo, os sertões do Paraíba do Sul, da Mantiqueira, do rio Pomba, do rio Doce e tantos outros. (IBGE, 2009, p. 26)
\end{abstract}

Deste modo, reconhece-se que o Brasil é um país de vários sertões, sejam eles constituídos por uma herança imaterial da história agrária, pelas construções literárias, ou por estudos geográficos que imprecisam da realidade do sertão ser aquela terra sofrida e longe do litoral, como é o caso dos Sertões do Leste.

\title{
4 UMA HISTÓRIA EM CONCLUSÃO
}

A história do sertão e do sertanejo recebeu ao longo dos tempos uma série de percepções diferenciadas. A análise dos estudiosos acerca do tema perpassa pela referência através do seu "olhar", da sua observação para a construção do pensamento social brasileiro sobre essas temáticas.

Por meio dessa revisão bibliográfica foi possível perceber que ao longo da história as figuras do sertão e do sertanejo no Brasil foram construídas de formas diferenciadas, ora trazendo o sertão como espaço antagônico ao litoral, ora trazendo o sertão como o ambiente seco, terra ignota e de natureza rebelde.

O sertão já foi classificado por seu contexto político, como a terra que contrariava a expansão da coroa portuguesa, o início da República, ou mesmo sendo aquela que mais necessita de políticas públicas para subsistência de seu povo devido seu atraso civilizatório.

O sertanejo sendo visto como aquele que era detentor de uma força absurda, como herói, tal como em Canudos, ora sendo abordado como o degenerado, é o caipira, o abandonado pelas políticas públicas às doenças tropicais, ao atraso econômico, educacional e afastado de qualquer debate político, mas também aquele que em tudo dá um "jeitinho" em nome de sua própria sobrevivência.

As percepções sociais, culturais e históricas traçadas para o sertão e para o sertanejo, na atualidade, são complementadas e redefinidas também pelas questões geográficas, fisiográficas, mantidas as tradições seculares das terras e dos povos já designados como sertanejos.

Por fim, pode-se salientar que o Brasil é um país de vários sertões e que sua história segue em conclusão, posto que as visões históricas trabalhadas pela literatura ainda estão enraizadas no pensamento social brasileiro. Ora se vê o sertão como um paraíso, ora como um purgatório e ora como inferno, com todas as concepções traçados do seu povo nestes contextos.

\section{REFERÊNCIAS}

AB'SABER, Aziz Nacib. Sertões e sertanejos: uma geografia humana sofrida. In: Estud. Av. vol.13 no.36. São Paulo May/Aug. 1999. Disponível em: <http://dx.doi.org/10.1590/S010340141999000200002>. Acesso em: 05 abr. de 2018.

IBGE. Atlas das representações literárias de regiões brasileiras. Sertões Brasileiros. Vol 2. Coordenação de Geografia. Rio de Janeiro: IBGE, 2006. rev. 2009.

CAMINHA, Pero Vaz. A CARTA DE PERO VAZ DE CAMINHA. Disponível em: <http://www.biblio.com.br/defaultz.asp?link=http://www.biblio.com.br/conteudo/perovazcaminha/carta.h tm>. Acesso em: 05 abr. 2018.

CARDOSO, Sérgio. O olhar viajante (do etnólogo). In: Novaes, Adauto (org.). O olhar. São Paulo: Companhia das Letras, 1988.

CARVALHO, Carlota. O Sertão: subsídios para a história e geografia do Brasil. Organização Adalberto Franklin e João Renor F. de Carvalho. 3.ed.rev.e ampl. - Teresina: EDUFPI, 2011. 
CHAUI, Marilena. BRASIL: Mito fundador e sociedade autoritária. 5. reimp. São Paulo: Editora Fundação Perseu Abramo, 2004.

CUNHA, Euclides da. [1902]. Os Sertões. Campanha de Canudos. Rio de Janeiro: Francisco Alves, 1995.

ESCÓRCIO, Maíra Leite. “O SERTÃO É UM MUNDO”. Uma aproximação fenomenológica dos modos de ser-no-mundo de sertanejos do semiárido nordestino. Dissertação de Mestrado. (Mestrado em Psicologia). Universidade Federal do Rio Grande do Norte. Natal, 2016. Disponível em: <https://repositorio.ufrn.br/jspui/handle/123456789/23376>. Acesso em: 24 mar. 2018.

LINHARES, Andrey Aparecido Caetano. A PRODUÇÃo E A REPRODUÇÃO DA IDENTIDADE CULTURAL CAIPIRA EM MOSSÂMEDES - GO. Dissertação de Mestrado. (Mestrado em Sociologia). Universidade Federal do Goiás. Goiânia, 2005. Disponível em: < https://possociologia.cienciassociais.ufg.br/up/109/o/Andrey.pdf>. Acesso em: 10 abr. 2018.

OLIVEIRA, Lúcia Lippi. A conquista do espaço: sertão e fronteira no pensamento brasileiro. Hist. cienc. Saúde-Manguinhos [online]. 1998, vol 5. Disponível em: <http://www.scielo.br/scielo.php?pid=S0104-59701998000400011\&script=sci_abstract\&tlng=pt>.

Acesso em: 06 mar. de 2018.

Americanos. Representações da identidade nacional no Brasil e nos EUA. Belo Horizonte: Editora UFMG, 2000

PALMA, Ana. Monteiro Lobato e a gênese do Jeca Tatu. Disponível em: https://agencia.fiocruz.br/monteiro-lobato-e-a-g\%C3\%AAnese-do-jeca-tatu. Editora Senac, 2006. Acesso em: 20 mar. de 2018.

SUASSUNA, Ariano. Auto da Compadecida. 1955. Disponível em: $<$ https://moodle.ufsc.br/pluginfile.php/1905669/mod_resource/content/1/Auto\%20da\%20Compadecida.p df>. Acesso em: 19 fev. de 2018.

Informações sobre os autores: PRPSMD: Doutoranda em História pela UNISINOS-RS. Mestra em Direito, Relações Internacionais e Desenvolvimento pela PUC-GO. Bacharel em Direito pela Universidade Federal do Maranhão.

Contribuição dos autores: PRPSMD: conceitualização, captação de recursos, supervisão, redação. 